\title{
Safety and Efficacy of Landiolol Hydrochloride in Children with Tachyarrhythmia of Various Etiologies
}

\author{
Atsuko Ashida ${ }^{1}$ (D) Noriyasu Ozaki ${ }^{1} \cdot$ Kanta Kishi $^{1} \cdot$ Yutaka Odanaka $^{1} \cdot$ Shintaro Nemoto $^{2} \cdot$ Hayato Konishi $^{2}$. \\ Akira Ashida ${ }^{1}$
}

Received: 5 March 2021 / Accepted: 26 May 2021 / Published online: 7 June 2021

(c) The Author(s) 2021

\begin{abstract}
The safety and efficacy of landiolol have not been fully elucidated in pediatric patients. This study aimed to clarify the safety and efficacy of landiolol in a pediatric cohort. We retrospectively assessed the clinical features of 21 pediatric patients who were administered landiolol at our hospital. We also investigated the rates of sinus rhythm conversion and heart rate response. The median patient age was 7 months (interquartile range 1-13 months). The etiology of tachyarrhythmia was junctional ectopic tachycardia in 10 patients (47.6\%), atrial tachycardia in 10 patients (47.6\%), and ventricular tachycardia in 1 patient (4.8\%). Of the 21 children, 18 (85.7\%) had congenital heart defects, including $14(77.8 \%)$ in whom a landiolol infusion was performed perioperatively. The landiolol infusion was effective in 18 pediatric patients $(85.7 \%)$, as measured by the conversion to sinus rhythm or a reduced heart rate. Atrial tachycardia in the perioperative period was terminated in all patients. Of 7 patients with tachyarrhythmias unrelated to the perioperative period, landiolol was effective in 5 . No adverse effects were reported in any patient. Landiolol infusion is effective and safe in pediatric patients with tachyarrhythmia of various etiologies, especially those with atrial tachyarrhythmia during the perioperative period.
\end{abstract}

Keywords Landiolol hydrochloride $\cdot$ Tachyarrhythmia $\cdot$ Children $\cdot$ Rate control $\cdot$ Rhythm control $\cdot$ Congenital heart defects

\section{Introduction}

Landiolol is an ultra-short-acting beta-blocker that can be administered intravenously. In adult patients, the efficacy and safety of landiolol have been confirmed in large cohorts using a double blind-case-controlled study [1,2]. Landiolol was initially indicated during the intra- and perioperative periods of cardiac surgery. However, the $2013 \mathrm{~J}$-Land study reported that landiolol is also effective for perioperative tachyarrhythmia unrelated to cardiac surgery [2].

In contrast, few studies have described the use of landiolol in pediatric patients [3-7]. We believe that landiolol is effective and safe for pediatric patients and aimed to reveal

Atsuko Ashida

atsuko.ashida@ompu.ac.jp

1 Department of Pediatrics, Osaka Medical and Pharmaceutical University, 2-7 Daigaku-machi, Takatsuki, Osaka 569-8686, Japan

2 Department of Pediatric Thoracic and Cardiovascular Surgery, Osaka Medical and Pharmaceutical University, Takatsuki, Osaka, Japan the efficacy and safety through our single-center experience of administering landiolol to pediatric patients with tachyarrhythmia with various etiologies.

\section{Materials and Methods}

We retrospectively reviewed the data of pediatric patients in whom an infusion of landiolol was performed to treat tachyarrhythmia between January 2009 and July 2020 at Osaka Medical College Hospital. We collected data regarding patient characteristics, congenital heart disease, the diagnosis and etiology of tachyarrhythmia, the type of cardiac surgery, the dose of the landiolol infusion, the pre-and postinfusion heart rate and blood pressure, and the conversion to sinus rhythm. The post-values were taken one hour after reaching the maximum dose of landiolol. We determined that landiolol was effective if the tachyarrhythmia was converted to sinus rhythm (achieved rhythm control) or the heart rate was reduced by more than $20 \%$ (achieved rate control) [4]. To evaluate the safety, we monitored and investigated the adverse events related to landiolol, such as bradycardia, 
arrhythmia, hypotension, cardiac dysfunction, hypoglycemia, and respiratory changes due to bronchial spasms.

We initiated the landiolol without a loading dose for all children of our cohort. The dose of initiation was 1 to $5 \mu \mathrm{g} / \mathrm{kg} / \mathrm{min}$. We titrated the dose up to $40 \mu \mathrm{g} / \mathrm{kg} / \mathrm{min}$ if the efficacy was not sufficient and the adverse events were not detected. We did not change the protocol based on the etiology of the arrhythmia.

Continuous data are presented as mean \pm standard deviation. Categorical data are presented as number (percentage). The pre-and post-infusion heart rate and blood pressure were compared using the paired $t$ test. JMP Pro version 14 statistical software (SAS Institute Inc., Cary, NC, USA) was used for all statistical analyses. Statistical significance was set at $P<0.05$.

The Institutional Review Board of the Osaka Medical College approved this study, and informed consent was obtained via opt-out due to the retrospective nature of this study.

\section{Results}

Twenty-one pediatric patients with tachyarrhythmia of various etiologies were treated with landiolol from January 2007 to July 2020 at Osaka Medical College Hospital. Patient characteristics are shown in Table 1. The median age at the initiation of landiolol was 7 months (interquartile range (IQR) 1-13 months). The median body weight was $6.8 \mathrm{~kg}$ (IQR 4-8.6 kg). Eighteen patients (85.7\%) had congenital heart disease, and 14 (66.7\%) patients had perioperative tachyarrhythmia related to cardiac surgery. Ten patients $(47.6 \%)$ were diagnosed with atrial tachycardia (AT), 10 patients $(47.6 \%)$ with junctional ectopic tachycardia (JET), and 1 patient (4.8\%) with ventricular tachycardia. Perioperative tachyarrhythmia related to cardiac surgery occurred in 6 patients $(60 \%)$ with AT and 8 patients $(80 \%)$ with JET.

Table 2 shows the dose of landiolol and the response to landiolol in each patient. The median maximum dose of landiolol was $11 \mu \mathrm{g} / \mathrm{kg} / \mathrm{min}$ (IQR $8-19.5 \mu \mathrm{g} / \mathrm{kg} / \mathrm{min}$ ). Sinus

Table 1 Patient demographics

\begin{tabular}{|c|c|c|c|c|c|c|}
\hline Patient & Age (months) & Sex & $\begin{array}{l}\text { Body weight } \\
(\mathrm{kg})\end{array}$ & Diagnosis of congenital heart defects & $\begin{array}{l}\text { Related to cardiac } \\
\text { surgery }\end{array}$ & $\begin{array}{l}\text { Etiology of } \\
\text { arrhythmia }\end{array}$ \\
\hline 1 & 91 & M & 15 & SLV, PA s/p TCPC & No & AT \\
\hline 2 & 7 & M & 8 & PAIVS, s/p BTS s/p RVOTR & Yes & AT \\
\hline 3 & 50 & M & 18 & Normal heart & No & AT \\
\hline 4 & 1 & $\mathrm{~F}$ & 3.6 & HLHS s/p Norwood operation & Yes & AT \\
\hline 5 & 3 & $\mathrm{~F}$ & 4.7 & TAPVC (supracardiac type) s/p TAPVC repair & Yes & AT \\
\hline 6 & 13 & M & 7.2 & $\begin{array}{l}\text { Noonan syndrome, ASD secundum type, vPS s/p } \\
\text { ASD closure, pulmonary valvotomy }\end{array}$ & Yes & AT \\
\hline 7 & 0.8 & M & 3.3 & TGA with VSD s/p arterial switch operation & Yes & AT \\
\hline 8 & 1 & M & 4.4 & Normal heart & No & AT \\
\hline 9 & 9 & $\mathrm{~F}$ & 8.5 & $\begin{array}{l}\text { Rupture of the mitral chordae tendineae with mas- } \\
\text { sive mitral valve regurgitation }\end{array}$ & Yes & AT \\
\hline 10 & 33 & $\mathrm{~F}$ & 10.2 & Trisomy 18, VSD s/p PAB, s/p ICR & No & AT \\
\hline 11 & 26 & $\mathrm{~F}$ & 11 & RIH, SV, PA, TAPVC s/p TAPVC repair & No & JET \\
\hline 12 & 0.4 & M & 2.5 & RIH, SA, SV, TAPVC s/p TAPVC repair & Yes & JET \\
\hline 13 & 2 & $\mathrm{~F}$ & 4 & SRV, DORV, ASD s/p Norwood type operation & Yes & JET \\
\hline 14 & 12 & $\mathrm{~F}$ & 5.1 & RIH, SRV, s/p BDG operation & No & JET \\
\hline 15 & 4 & M & 5.1 & Trisomy 21 , cAVSD & Yes & JET \\
\hline 16 & 22 & $\mathrm{~F}$ & 8.6 & Trisomy 18, VSD s/p PAB, s/p ICR & Yes & JET \\
\hline 17 & 6 & M & 8.1 & TOF $\mathrm{s} / \mathrm{p}$ total correction & Yes & JET \\
\hline 18 & 8 & M & 6.8 & TOF $s / p$ total correction & Yes & JET \\
\hline 19 & 7 & M & 8.8 & Dextrocardia, DORV, vPS, VSD s/p ICR & Yes & JET \\
\hline 20 & 0.3 & $\mathrm{~F}$ & 3 & TGA with IVS & Yes & JET \\
\hline 21 & 0.6 & $\mathrm{~F}$ & 3.5 & Normal heart & No & VT \\
\hline
\end{tabular}

$M$ male, $F$ female, $S L V$ single left ventricle, $P A$ pulmonary atresia, $T C P C$ total cava pulmonary connection, PAIVS pulmonary atresia with intact ventricular septum, BTS Blalock-Taussig shunt, RVOTR right ventricular outflow reconstruction, HLHS hypoplastic left heart syndrome, TAPVC total anomalous of pulmonary vein connection, $A S D$ atrial septal defect, $v P S$ valvular pulmonary stenosis, $T G A$ transposition of great arteries, $V S D$ ventricular septal defect, $P A B$ pulmonary artery banding, $I C R$ intracardiac repair, $R I H$ right isomerism heart, $S V$ single ventricle, $S A$ single atrium, $S R V$ single right ventricle, $D O R V$ double-outlet right ventricle, $B D G$ bidirectional Glenn, cAVSD complete atrioventricular defect, $T O F$ tetralogy of Fallot, IVS intact ventricular septum, $A T$ atrial tachycardia, JET junctional ectopic tachycardia, $V T$ ventricular tachycardia 
Table 2 Dose and effectiveness of landiolol infusion

\begin{tabular}{|c|c|c|c|c|c|c|c|c|}
\hline Patient & $\begin{array}{l}\text { Maximum dose of } \\
\text { landiolol hydro- } \\
\text { chloride }(\mu \mathrm{g} / \mathrm{kg} / \\
\mathrm{min})\end{array}$ & $\begin{array}{l}\text { Sinus } \\
\text { conver- } \\
\text { sion }\end{array}$ & $\begin{array}{l}\text { Achieved } \\
\text { rate control }\end{array}$ & $\begin{array}{l}\text { Effectiveness } \\
\text { of landiolol }\end{array}$ & $\begin{array}{l}\text { Pre-infusion heart } \\
\text { rate (beats per } \\
\text { minute) }\end{array}$ & $\begin{array}{l}\text { Post-infusion } \\
\text { heart rate (beats } \\
\text { per minute) }\end{array}$ & $\begin{array}{l}\text { Pre-infusion } \\
\text { blood pressure } \\
(\mathrm{mmHg})\end{array}$ & $\begin{array}{l}\text { Post-infusion } \\
\text { blood pressure } \\
(\mathrm{mmHg})\end{array}$ \\
\hline 1 & 4 & Yes & Yes & Yes & 130 & 80 & 86 & 90 \\
\hline 2 & 5 & Yes & Yes & Yes & 200 & 150 & 96 & 94 \\
\hline 3 & 40 & No & Yes* & Yes & 220 & 160 & 100 & 102 \\
\hline 4 & 12.5 & Yes & Yes & Yes & 160 & 120 & 60 & 66 \\
\hline 5 & 3.7 & Yes & Yes & Yes & 200 & 140 & 80 & 76 \\
\hline 6 & 11 & Yes & Yes & Yes & 230 & 130 & 68 & 86 \\
\hline 7 & 5.6 & Yes & Yes & Yes & 190 & 150 & 70 & 78 \\
\hline 8 & 5 & Yes & Yes & Yes & 210 & 130 & 85 & 90 \\
\hline 9 & 21 & Yes & Yes & Yes & 220 & 130 & 80 & 90 \\
\hline 10 & 40 & No & Yes* & Yes & 200 & 160 & 95 & 95 \\
\hline 11 & 10 & Yes & Yes & Yes & 200 & 90 & 88 & 102 \\
\hline 12 & 10 & No & Yes* & Yes & 200 & 160 & 65 & 70 \\
\hline 13 & 8 & Yes & Yes & Yes & 210 & 150 & 70 & 70 \\
\hline 14 & 30 & No & No & No & 230 & 230 & 75 & 70 \\
\hline 15 & 15 & Yes & Yes & Yes & 180 & 120 & 67 & 80 \\
\hline 16 & 9.5 & Yes & Yes & Yes & 170 & 120 & 77 & 119 \\
\hline 17 & 40 & No & No & No & 230 & 230 & 69 & 67 \\
\hline 18 & 15 & Yes & Yes & Yes & 180 & 130 & 81 & 111 \\
\hline 19 & 19.5 & No & Yes* & Yes & 185 & 140 & 76 & 67 \\
\hline 20 & 10 & Yes & Yes & Yes & 207 & 145 & 87 & 75 \\
\hline 21 & 19 & No & No & No & 130 & 130 & 88 & 90 \\
\hline
\end{tabular}

No adverse events were reported in any patient

Rate control is defined as $a \geq 20 \%$ reduction in heart rate

*Sinus conversion was not achieved, but rhythm control could be achieved by landiolol infusion

conversion (rhythm control) was achieved in 14 patients (66.7\%), and heart rate reduction (rate control) was achieved in four patients (19.0\%) in whom sinus conversion could not be achieved; therefore, landiolol was effective in 18 patients (85.7\%). Landiolol was effective in $71.4 \%$ of patients with tachyarrhythmia not related to cardiac surgery. Landiolol successfully controlled AT in all patients and JET in 8 patients (80\%). Landiolol was effective in $50 \%$ of patients with JET unrelated to cardiac surgery and in $87.5 \%$ of patients with JET related to cardiac surgery. Landilol could not terminate VT in our cohort. There were no adverse events related to landiolol infusion in any patient.

The infusion of landiolol significantly reduced the heart rate $(p<0.0001 ;$ Fig. 1$)$ and significantly increased the blood pressure ( $p=0.0421$; Fig. 2$)$.

\section{Discussion}

Landiolol effectively controlled the heart rhythm or rate in $18 / 21$ pediatric patients $(85.7 \%$ ) in this study with no adverse events. All patients with AT were effectively treated, and landiolol was also effective in patients with JET, especially in the postoperative period.

\section{Efficacy of Landiolol in the Perioperative and Non-perioperative Periods}

Few studies have described the efficacy of landiolol in pediatric patients [3-7], and those studies reported patients with tachyarrhythmia in the perioperative period of cardiac surgery. The efficacy of landiolol in pediatric patients in settings other than the postoperative period has only been reported in case reports $[8,9]$. This study reports the efficacy of landiolol in pediatric patients in the postoperative period and at times unrelated to cardiac surgery, as it includes seven patients who did not undergo surgery and received landiolol. Landiolol was found to be effective in five patients (71.4\%) who did not undergo surgery and in 13 patients (92.9\%) who underwent cardiac surgery. These results suggest that landiolol is more effective for tachyarrhythmia related to cardiac surgery in pediatric patients, especially during the perioperative period. The increase of intrinsic catecholamines can induce tachyarrhythmia, including AT 


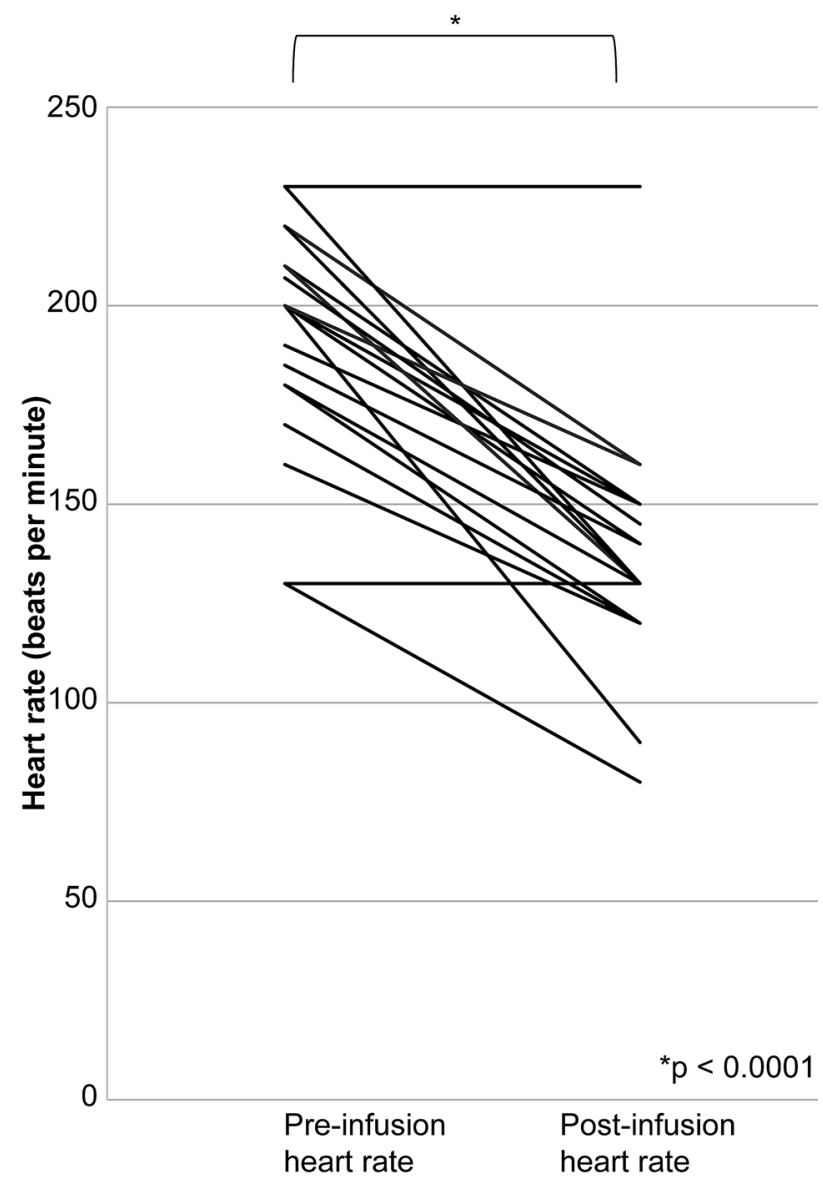

Fig. 1 Heart rate, before and after landiolol infusion. The changes in heart rate before and after the infusion of landiolol hydrochloride are shown. Landiolol significantly reduced the heart rate

and JET postoperatively, due to an increased automaticity mechanism. Landiolol can reduce the efficacy of intrinsic catecholamines that induce JET or AT [10]. However, tachyarrhythmia with an arrhythmogenic substrate may be refractory to landiolol. We could not achieve rhythm control in some children of our cohort. The etiology of arrhythmia in those children might be related to the substrate, such as re-entry mechanisms. Landiolol suppresses the conduction of the atrioventricular node and reduces the ventricular rate that can lead to achieved rate control for arrhythmias with the reentrant mechanism. However, landiolol cannot suppress reentrant arrhythmias and not achieve rhythm control for those because landiolol suppresses the onset of action potentials but does not prolong the refractory period.

\section{Comparing Landiolol and Esmolol}

Landiolol is an ultra-short-acting and beta-one selective beta-blocker that is administered intravenously [11, 12]. Landiolol is produced by a Japanese company and is available in

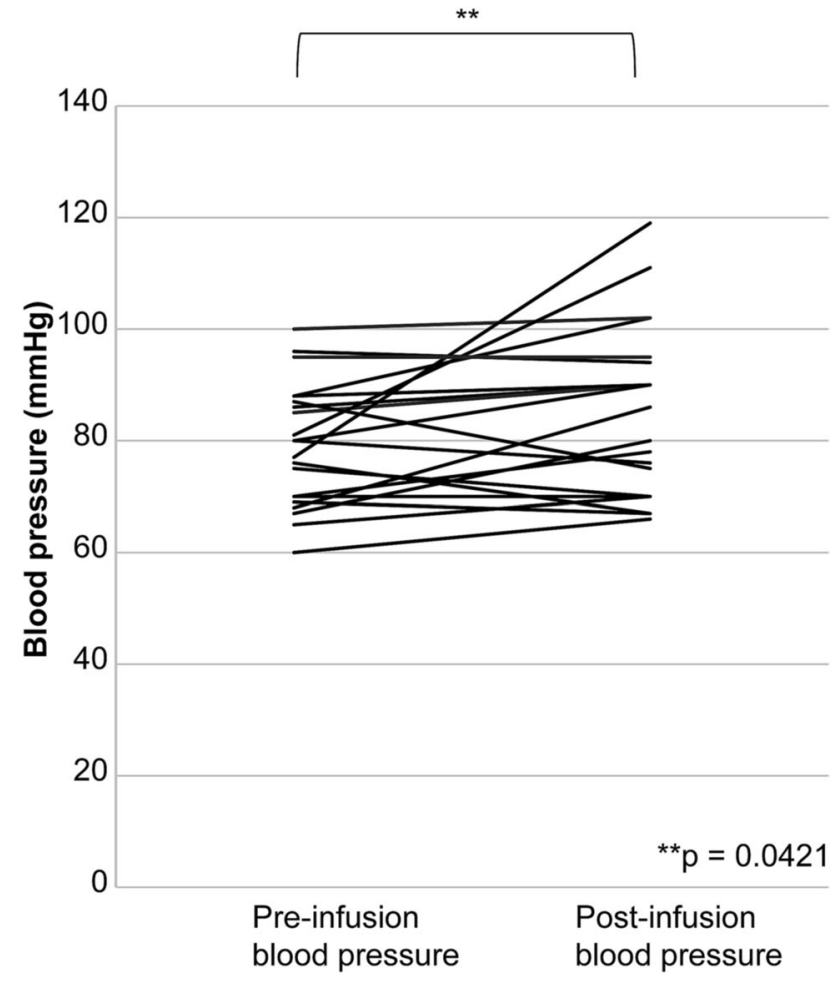

Fig. 2 Blood pressure before and after landiolol infusion. The blood pressures before and after the infusion of landiolol hydrochloride are shown. Landiolol significantly increased the blood pressure

Japan. The half-life of landiolol is approximately four minutes, which is the shortest among beta-blocker compounds to date. Landiolol has a strong affinity to the beta-one receptor, which is the most dominant beta-adrenergic receptor in the heart. Landiolol has high selectivity to beta-one adrenergic receptors with a $\$ 1 / \beta 2$ ratio of 255 . Esmolol is another ultra-short-acting and cardio-selective beta-adrenoreceptor blocker that is available worldwide [13, 14]. Compared with esmolol, landiolol has a shorter half-life and better affinity to beta-one adrenoreceptors [15]. While esmolol can result in hypotension, landiolol does not [16]; however, some studies have reported that esmolol is more effective at lowering blood pressure than landiolol $[17,18]$. The serum level of landiolol must be high enough to terminate tachyarrhythmia $[11,12]$. The short half-life of landiolol allows for a rapid infusion of a sufficient dose to achieve sufficient serum levels. The potent cardio-selectivity of landiolol decreases the risk of hypotension, even at high doses. Therefore, landiolol is applicable in pediatric patients with low cardiac function postoperatively or tachycardia-induced cardiomyopathy.

From the standpoint of the anti-arrhythmic effect, esmolol might be somewhat weak. Trippel et al. reported that the effect of esmolol to suppress sustained supraventricular tachycardia was recognized in only one out of 4 children with reentrant supraventricular tachycardia. Regarding 
automatic supraventricular tachycardia, esmolol could not suppress tachycardia in a child with an automatic mechanism [19]. Therefore, we consider that landiolol is more efficient and safe than esmolol for children, especially in the perioperative setting.

\section{Landiolol in Adult Patients Compared to Pediatric Patients}

The J-Land study investigated the efficacy of landiolol in adult patients with atrial fibrillation and impaired left ventricular function and found that landiolol effectively controls the heart rate in these patients [2]. According to previous studies, the rate of sinus rhythm conversion (achieved rhythm control) is $2.2-26 \%[1,2]$. In this study, the rate of sinus rhythm conversion was $66.7 \%$. This discrepancy between children and adults regarding the rate of rhythm control could be originated from the difference in the etiologies of arrhythmias. The etiologies were junctional ectopic tachycardia and atrial ectopic tachycardia for children of our cohort and atrial fibrillation and atrial flutter for adult cases. Depending on the patient's clinical status and arrhythmic etiology, rate control may be the target treatment for tachyarrhythmia in adult patients. However, in pediatric patients with fragile hemodynamics (such as after cardiac surgery), rhythm control improves the fragile hemodynamics, suggesting that landiolol would be effective as a first-line treatment in these patients.

\section{Safety-Related Features of Landiolol}

Due to landiolol's ultra-short half-life, adverse effects can be avoided by stopping the infusion $[11,12]$. Other antiarrhythmic agents, such as amiodarone, flecainide, and sotalol have also been reported as effective in pediatric patients [20-25]. However, these drugs have longer halflives and, therefore, adverse effects cannot be stopped as quickly as the adverse effects of landiolol. Moreover, landiolol exhibits beta-one adrenoreceptor selectivity, which reduces the adrenergic effect of intrinsic catecholamines on the heart rate without the negative inotropic effects on cardiac and other tissues.

\section{Limitations}

This retrospective study was conducted using data from a single center, and therefore, included a small number of patients. The actual effect of landiolol could not be evaluated in this study due to the retrospective design. While we did not restrict the criteria for landiolol infusion, the possibility of a selection bias cannot be ruled out.

\section{Conclusion}

Landiolol is effective and safe in pediatric patients with tachyarrhythmia of various etiologies, including those unrelated to cardiac surgery. Landiolol is most effective during the perioperative period in pediatric patients with AT.

Acknowledgements Special thanks to PhD. Tomoyuki Yamada, Department of Pharmaceutics, Osaka Medical and Pharmaceutical University Hospital for advice regarding the pharmacokinetics of drugs. We thank Editage for providing English editing of our manuscript.

Author Contributions All authors contributed to the study conception and design. Material preparation, data collection, and analysis were performed by AA, NO, and KK. The first draft of the manuscript was written by AA, and all authors commented on previous versions of the manuscript. All authors read and approved the final manuscript.

Funding The authors did not receive support from any organization for the submitted work.

Data Availability The database generated and analyzed during the current study are proprietary and cannot be shared under the conditions of our data use agreement.

Code Availability Microsoft Office, JMP Pro version 14 statistical software (SAS Institute Inc., Cary, NC, USA).

\section{Declarations}

Conflict of interest The authors have no relevant financial or non-financial interests to declare.

Ethical Approval The authors assert that all procedures contributing to this work comply with the ethical standards of the Ethical Guidelines for Medical and Health Research Involving Human Subjects and with the Helsinki Declaration of 1975, as revised in 2008, and has been approved by The Institutional Review Board of the Osaka Medical College (2020-039).

Informed Consent Informed consent was obtained via opt-out due to the retrospective nature of this study.

Open Access This article is licensed under a Creative Commons Attribution 4.0 International License, which permits use, sharing, adaptation, distribution and reproduction in any medium or format, as long as you give appropriate credit to the original author(s) and the source, provide a link to the Creative Commons licence, and indicate if changes were made. The images or other third party material in this article are included in the article's Creative Commons licence, unless indicated otherwise in a credit line to the material. If material is not included in the article's Creative Commons licence and your intended use is not permitted by statutory regulation or exceeds the permitted use, you will need to obtain permission directly from the copyright holder. To view a copy of this licence, visit http://creativecommons.org/licenses/by/4.0/. 


\section{References}

1. Kakihana Y, Nishida O, Taniguchi T, Okajima M, Morimatsu H, Ogura H, Yamada Y, Nagano T, Morishima E, Matsuda N, on behalf of the J-Land 3S Study Group (2020) Efficacy and safety of landiolol, an ultra-short-acting $\beta 1$-selective antagonist, for treatment of sepsis-related tachyarrhythmia (J-Land 3S): a multicentre, open-label, randomised controlled trial. Lancet Respir Med 8:863-872. https://doi.org/10.1016/S2213-2600(20)30037-0

2. Nagai R, Kinugawa K, Inoue H, Atarashi H, Seino Y, Yamashita T, Shimizu W, Aiba T, Kitakaze M, Sakamoto A, Ikeda T, Imai Y, Daimon T, Fujino K, Nagano T, Okamura T, Hori M, Okamura T, Hori M, J Land Investigators (2013) Urgent management of rapid heart rate in patients with atrial fibrillation/flutter and left ventricular dysfunction: comparison of the ultra-short-acting $\beta 1$-selective blocker landiolol with digoxin (J-Land Study). Circ J 77:908-916. https://doi.org/10.1253/circj.CJ-12-1618

3. Saiki H, Nakagawa R, Ishido H, Masutani S, Senzaki H (2013) Landiolol hydrochloride infusion for treatment of junctional ectopic tachycardia in post-operative paediatric patients with congenital heart defect. Europace 15:1298-1303. https://doi.org/ 10.1093/europace/eut044

4. Tokunaga C, Hiramatsu Y, Kanemoto S, Takahashi-Igari M, Abe M, Horigome H, Sakakibara Y (2013) Effects of landiolol hydrochloride on intractable tachyarrhythmia after pediatric cardiac surgery. Ann Thorac Surg 95:1685-1688. https://doi.org/10.1016/j. athoracsur.2013.01.057

5. Yoneyama F, Tokunaga C, Kato H, Nakajima T, Mathis BJ, Sakamoto H, Hiramatsu Y (2018) Landiolol hydrochloride rapidly controls junctional ectopic tachycardia after pediatric heart surgery. Pediatr Crit Care Med 19:713-717. https://doi.org/10.1097/PCC. 0000000000001573

6. Hasegawa T, Oshima Y, Maruo A, Matsuhisa H, Kadowaki T, Noda R (2013) Landiolol for junctional ectopic tachycardia refractory to amiodarone after pediatric cardiac surgery. Gen Thorac Cardiovasc Surg 61:350-352. https://doi.org/10.1007/ s11748-012-0141-0

7. Maehata Y, Nishigaki K, Kawahira Y, Yanase G, Sugita R (2011) The efficacy of landiolol against junctional ectopic tachycardia after pediatric cardiac surgery-a novel treatment of ultrashort-acting beta-adrenergic blocker in congenital heart disease-report of two cases. Prog Med 31:601-604

8. Fujita S, Futatani T, Kubo T, Itamochi M, Yachi Y, Iwasaki H, Shimao A, Ina S, Higashiyama H, Igarashi N, Hatasaki K (2017) Virus myocarditis in a 1-month-old boy presenting as two types of paroxysmal supraventricular tachycardia. Pediatr Int 59:627-632. https://doi.org/10.1111/ped.13261

9. Oka H, Sugimoto M, Azuma H (2016) Efficacy of landiolol for the treatment of junctional ectopic tachycardia resulting from sepsis. Cardiol Young 26:183-187. https://doi.org/10.1017/S104795111 5000244

10. Tan C-K, Glisson SN, El-Etr AA, Ramakrishnaiah KB (1976) Levels of circulating norepinephrine and epinephrine before, during, and after cardiopulmonary bypass in man. J Thorac Cardiovasc Surg 71:928-931. https://doi.org/10.1016/S0022-5223(19) 40133-5

11. Iguchi S, Iwamura H, Nishizaki M, Hayashi A, Senokuchi K, Kobayashi K, Sakaki K, Hachiya K, Ichioka Y, Kawamura M (1992) Development of a highly cardioselective ultra short-acting betablocker, ONO-1101. Chem Pharm Bull 40:1462-1469. https://doi. org/10.1248/cpb.40.1462

12. Murakami M, Furuie H, Matsuguma K, Wanibuchi A, Kikawa S, Irie $S$ (2005) Pharmacokinetics and pharmacodynamics of landiolol hydrochloride, an ultra short-acting beta1-selective blocker, in a dose escalation regimen in healthy male volunteers. Drug Metab Pharmacokinet 20:337-344. https://doi.org/10.2133/dmpk.20.337
13. Wiest DB, Trippel DL, Gillette PC, Garner SS (1991) Pharmacokinetics of esmolol in children. Clin Pharmacol Ther 49:618623. https://doi.org/10.1038/clpt.1991.78

14. Yu SK, Tait G, Karkouti K, Wijeysundera D, McCluskey S, Beattie WS, Stuart McCluskey W, Beattie S (2011) The safety of perioperative esmolol: a systematic review and meta-analysis of randomized controlled trials. Anesth Analg 112:267-281. https:// doi.org/10.1213/ANE.0b013e3182025af7

15. Sasao J, Tarver SD, Kindscher JD, Taneyama C, Benson KT, Goto H (2001) In rabbits, landiolol, a new ultra-short-acting $\beta$-blocker, exerts a more potent negative chronotropic effect and less effect on blood pressure than esmolol. Can J Anaesth 48:985-989. https:// doi.org/10.1007/BF03016588

16. Sugiyama A, Takahara A, Hashimoto K (1999) Electrophysiologic, cardiohemodynamic and $\beta$-blocking actions of a new ultrashort-acting $\beta$-blocker, ONO-1101, assessed by the in vivo canine model in comparison with esmolol. J Cardiovasc Pharmacol 34:70-77. https://doi.org/10.1097/00005344-199907000-00012

17. Tabbutt S, Nicolson SC, Adamson PC, Zhang X, Hoffman ML, Wells W, Backer CL, McGowan FX, Tweddell JS, Bokesch P, Schreiner M (2008) The safety, efficacy, and pharmacokinetics of esmolol for blood pressure control immediately after repair of coarctation of the aorta in infants and children: a multicenter, double-blind, randomized trial. J Thorac Cardiovasc Surg 136:321328. https://doi.org/10.1016/j.jtcvs.2007.09.086

18. Krumpl G, Ulč I, Trebs M, Kadlecová P, Hodisch J, Maurer G, Husch B (2018) Pharmacokinetics and pharmacodynamics of low-, intermediate-, and high-dose landiolol and esmolol during long-term infusion in healthy whites. J Cardiovasc Pharmacol 71:137-146. https://doi.org/10.1097/FJC.0000000000000554

19. Trippel MD, Wiest DB, Gillette PC (1991) Cardiovascular and antiarrhythmic effects of esmolol in children. J Pediatr 119:142147. https://doi.org/10.1016/S0022-3476(05)81055-8

20. Entenmann A, Michel M, Herberg U, Haas N, Kumpf M, Gass M, Egender F, Gebauer R (2017) Management of postoperative junctional ectopic tachycardia in pediatric patients: a survey of 30 centers in Germany, Austria, and Switzerland. Eur J Pediatr 176:1217-1226. https://doi.org/10.1007/s00431-017-2969-x

21. Price JF, Kertesz NJ, Snyder CS, Friedman RA, Fenrich AL (2002) Flecainide and sotalol: a new combination therapy for refractory supraventricular tachycardia in children $<1$ year of age. J Am Coll Cardiol 39:517-520. https://doi.org/10.1016/s07351097(01)01773-9

22. Perry JC, McQuinn RL, Smith RT, Gothing C, Fredell P, Garson A (1989) Flecainide acetate for resistant arrhythmias in the young: efficacy and pharmacokinetics. J Am Coll Cardiol 14:185-191. https://doi.org/10.1016/0735-1097(89)90070-3 (discussion 192)

23. Perry JC, Garson A Jr (1992) Flecainide acetate for treatment of tachyarrhythmias in children: review of world literature on efficacy, safety, and dosing. Am Heart J 124:1614-1621. https://doi. org/10.1016/0002-8703(92)90081-6

24. Pfammatter JP, Paul T, Lehmann C, Kallfelz HC (1995) Efficacy and proarrhythmia of oral sotalol in pediatric patients. J Am Coll Cardiol 26:1002-1007. https://doi.org/10.1016/0735-1097(95) 00268-3

25. Fish FA, Gillette PC, Benson DW Jr (1991) Proarrhythmia, cardiac arrest and death in young patients receiving encainide and flecainide. The Pediatric Electrophysiology Group. J Am Coll Cardiol 18:356-365. https://doi.org/10.1016/0735-1097(91) 90586-x

Publisher's Note Springer Nature remains neutral with regard to jurisdictional claims in published maps and institutional affiliations. 